\title{
Study on the Realization Path of County Industrial Prosperity Under Rural Revitalization Strategy A Case Study of Hanyuan County, Sichuan Province
}

\author{
Binyu $\mathrm{Hu}^{1}$ Yaping Jiang ${ }^{1, *}$ \\ ${ }^{1}$ College of Commerce, Chengdu University, Chengdu, Sichuan 610000, China \\ *Corresponding author. Email: 604439648@qq.com
}

\begin{abstract}
The strategy of rural vitalization is a major historical task of Chinese society in the new development stage. Industrial prosperity is the key to the implementation of the strategy. As the basic unit of China's social governance and economic development, the area plays an important role in the national economy and plays an important role in the realization of the industry. Prosperity and promotion of rural revitalization are also important points. How to achieve industrial prosperity and promote rural revitalization based on the area is a problem worthy of study. Therefore, this article adopts literature research method, case research method, field investigation method and other research methods, taking Hanyuan in Sichuan Province as an example, to explore its path to achieve industrial prosperity in the context of rural revitalization strategy. It turns out that Hanyuan has adopted five types of promotion measures, but there are still some shortcomings. This article puts forward certain suggestions for its shortcomings, in order to help Hanyuan to achieve industrial prosperity, so as to provide meaningful information on how to use county as a focus to achieve industrial prosperity and promote rural revitalization.
\end{abstract}

Keywords: Rural revitalization, County, Industrial prosperity.

\section{INTRODUCTION}

In the report of the 19th National Congress of the Communist Party of China, Comrade Xi Jinping proposed the implementation of the strategy of rural revitalization, which clarified the general requirements of "prosperous industry, livable ecology, civilized rural customs, effective governance, and affluent life". Rural revitalization covers all aspects of the village. In the final analysis, it is a development issue, of which "industrial prosperity" is the focus. Only by prospering rural industries can we attract more foreign resources and talents, gather popularity and wealth, and promote rural economic development. It can be seen that the key to implementing the rural revitalization strategy is to promote industrial revitalization and achieve industrial prosperity. As a specific geographic space, county is the basic unit of China's social governance and economic development, and it plays an important role in the development of the national economy. From a spatial perspective, agriculture is mainly concentrated in counties, rural areas are mainly distributed in counties, and most farmers live in counties. The Fifth Plenary Session of the Nineteenth Central Committee of the Communist Party of China clearly stated that "to fully implement the strategy of rural revitalization, strengthen the use of industry to supplement agriculture and the city to lead the countryside, and promote the formation of a new type of industryagricultural relationship that promotes mutual promotion of industry and agriculture, and complements urban and rural development, coordinated development and common prosperity." This requires that when comprehensively promoting rural revitalization, we must firmly grasp the key point of "county area". When realizing industrial prosperity, it is necessary to focus on the area, coordinate the development of urban and rural areas, and give priority to the development of agriculture and rural areas. 
In summary, how to use county as a focus to achieve industrial prosperity and promote the full implementation of the rural revitalization strategy is a problem worthy of study. This article takes Hanyuan County, Sichuan Province, a representative in the process of realizing industrial prosperity, as an example, to explore its path to realizing industrial prosperity, hoping to provide meaningful information for realizing industrial prosperity and promoting rural revitalization with county as a focus.

\section{MEASURES AND EFFECTIVENESS OF INDUSTRIAL PROSPERITY IN HANYUAN COUNTY}

Hanyuan is located in the south of Ya'an City, Sichuan Province. Hanyuan covers an area of 2382 square kilometers, has 21 townships (towns), and has a population of nearly 330,000 . It is a typical mountainous agricultural area. The revitalization of industry in Hanyuan has important reference value for other neighboring areas. In recent years, the Hanyuan government has always put the "three rural" work as the county's top priority. Hanyuan makes full use of resources, industries, and location advantages to formulate area rural revitalization plans and rural industrial development plans to prosper area industry.

\subsection{Intensive Scale Education Industries}

Hanyuan implements the construction of a modern agricultural industry system in Sichuan Province and develops Hanyuan's tens of billions of mu of characteristic industries. Hanyuan actively guides small farmers to build characteristic industries that adapt to local conditions, builds "532" ten characteristic industrial bases of nearly $800,000 \mathrm{mu}$, creates 15 characteristic industrial towns, and establishes a national "one village, one product" demonstration base town, implemented by the province There are 2 advanced towns in the rural revitalization strategy and 3 demonstration villages.

\subsection{Infrastructure}

The area attaches particular importance to infrastructure construction, giving priority to the implementation of infrastructure projects such as high-standard farmland, rural roads and irrigation and water conservancy, with a highway smooth flow rate of 100 per cent and 100 per cent of established villages in the area to achieve road hardening and transformation in Tongcun.

\subsection{Featured Industry}

Hanyuan enjoys the reputation of "Hometown of Chinese Peppercorns". Hanyuan Peppercorns is mellow and refreshing. It sells well inside and outside the province, and is protected by National Geographical Indications. Hanyuan has developed this characteristic agricultural product in depth, and has cooperated with the Provincial Academy of Agricultural Sciences and other institutions to actively develop various characteristic products centered on Hanyuan Zanthoxylum bungeanum. It has established cooperative relations with 14 scientific research institutes to develop Zanthoxylum bungeanum edible products. There are more than 30 kinds of new products such as, medicine, chemical industry, health care, etc., and the output value of the whole industry chain of pepper reaches 2.1 billion yuan. In Hanyuan, agricultural experts formulated and released 10 sets of agricultural production technical regulations, cultivated 3 provincial-level excellent varieties, and the excellent and good rate of prickly ash characteristic industry reached $95 \%$.

In addition, Hanyuan has cooperated with Alibaba Cloud to create the country's first mountainous agricultural digital economy platform, build the Aniu Smart Agriculture Exhibition Hall, expand the sales and promotion channels of specialty products, and have been rated as "Internet + agricultural products from the village to the city pilot counties".

\subsection{Multi-measures and Strong Brand}

Hanyuan implemented the brand guidance and shaping plan and successfully registered the "Hanyuan Red" regional public brand with a brand value of 4.965 billion yuan.

\subsection{Integration of Agriculture and Tourism}

In accordance with the development concept of "agricultural landscaping, landscape ecologicalization, and ecological benefit", the area vigorously develops fruit and vegetable picking gardens and agricultural experience parks, builds a boutique tourism loop, and organically connects landscape nodes, characteristic industries and emerging formats, and holds special festivals. It has successively been named the province's strong rural 
tourism area and the province's rural tourism demonstration area.

Hanyuan has achieved certain development of Hanyuan's industries through the above five path plans, and initially revitalize industries, and the full realization of industrial prosperity is just around the corner.

\section{SHORTAGE AND OPTIMAL SUGGESTIONS OF MEASURES TO REALIZE INDUSTRIAL PROSPERITY IN HANYUAN COUNTY}

\subsection{Shortcomings}

\subsubsection{Industrial Quality}

At present, China's economy is changing from a high-speed growth stage to a high-quality development stage. The "establishment and improvement of an economic system for green and low-carbon circular development" proposed in the report of the Nineteenth National Congress of the Party has pointed out the direction for high-quality development in the new era. Rural industries must meet the requirements of the times and develop green high-quality industries. Hanyuan is a typical mountainous agricultural county, agriculture is the main supporting industry for area economic development, but at present, area agriculture is still dominated by traditional agriculture, green highquality industries account for less. Moreover, its agricultural sustainability is not strong, and its agricultural development needs to be improved.

\subsubsection{The Mass Forces}

The main body of rural industrial prosperity is the masses, the most fundamental motive force of industrial prosperity comes from the peasant masses, and the main force to realize industrial prosperity should also be the broad masses of peasants, which fully shows that industrial development needs to respect the opinions of the masses, arouse the initiative and enthusiasm of the masses, and give full play to the creativity of the masses. At present, the measures of prosperity industry in Hanyuan are mainly based on government decision-making, leading group overall arrangement as the leading group, cannot give full play to the power of the masses, and mass work needs to be improved.

\subsubsection{Policy Support Systems}

Economic development cannot be separated from relevant policy support. Against the background of rural revitalization, in order to realize the prosperity of industry, promote the development of economy and promote rural revitalization, it is necessary to improve the relevant policy support system so as to effectively promote the development and prosperity of rural industry. In Hanyuan County, the policy support system is not perfect when developing and prospering the industry, which cannot fully stimulate the vitality of industrial development, and the policy support system needs to be improved.

\subsection{Optimization Recommendations}

\subsubsection{Promoting Industrial Transformation and Upgrading and Promoting Green Agriculture}

Against the background of high quality development in the new era, Hanyuan should promote the transformation and upgrading of industries, plan the transformation and upgrading programs of high efficiency planting and green food industry, and promote the transformation and upgrading of agricultural industry.

\subsubsection{Giving Full Play to the Main Role of the Masses}

The development of rural industry should actively attract the participation of the masses, give full play to the main creative role of the masses, and cannot replace the masses to make decisions. In the next prosperous industrial work, Hanyuan should first do a good job in mass work, unify mass thinking, encourage the masses to participate extensively, give the masses creative opportunities, and fully mobilize the enthusiasm of the masses.

\subsubsection{Improved Policy Support Systems}

A sound policy support system can fully stimulate the vitality of industrial development. Hanyuan should improve the policy support system of industrial prosperity from two aspects: fiscal policy and talent policy. We should perfect the financial support system and the subsidy system of agricultural reform in order to promote industrial transformation and upgrading, and then realize green and high quality development. Secondly, we should reform the talent support system and train 
modern new farmers. The government should encourage more young talents to return to their hometowns to participate in agricultural construction.

\section{CONCLUSION}

"Industry prosperity" is of great significance in comprehensively promoting the strategy of rural revitalization. As the "grabbing point" of a thriving industry, counties should make plans, adopt various measures to revitalize the industry, and continuously optimize plans to achieve industrial prosperity and promote rural revitalization.

\section{AUTHORS' CONTRIBUTIONS}

Binyu $\mathrm{Hu}$ completed the preliminary research work and the writing of the paper. Yaping Jiang participated in the paper writing and data analysis.

\section{REFERENCES}

[1] Qin Xiao. The new path of county economic development under rural revitalization $[\mathrm{J}]$. Contemporary County Economy, 2021(03): 57-59. (In Chinese)

[2] Cheng Weishan. Carrying out Rural Revitalization and Focusing on Industrial Prosperity New Countryside, 2018(11):5-7. (In Chinese)

[3] Zeng Fusheng, Cai Baozhong. [J]. on the Realization of Hunan Rural Revitalization Strategy by Industrial Prosperity Research on Agricultural Modernization, 2018,39(02):179184. (In Chinese)

[4] Deng Yuexing. Strive to promote rural revitalization and start a new game [N]. Guiyang Daily, 2021-03-22(007). (In Chinese)

[5] Li Tie. What is the relationship between rural revitalization and new urbanization? [N]. Beijing Daily, 2021-03-22(011). (In Chinese)

[6] Wang Jianqiang. Provide solid talent support for comprehensively promoting rural revitalization [N]. Hebei Daily, 2021-03-19 (007). (In Chinese) 